\title{
A VUELTAS CON LA FIESTA TEATRAL DEL BARROCO ESPAÑOL: MODELOS, NORMAS Y RASGOS
}

\author{
Marcella Trambaioli \\ Dipartimento di Studi Umanistici \\ Università del Piemonte Orientale "Amedeo Avogadro» \\ Via Manzoni, 8 \\ 13100 Vercelli. Italia \\ marcella.trambaioli@1ett.unipmn.it
}

[Anuario calderoniano (ISSN: 1888-8046), vol. extra, 1, 2013, pp. 235-252]

A pesar de la cuantiosa bibliografia que se ha ido acumulando en las últimas décadas sobre la fiesta teatral cortesana de la España barroca, en los debates de los congresos y simposios internacionales se siguen escuchando preguntas y consideraciones de hispanistas en ciernes que parecen borrar ipso facto toda la labor crítica de tantos rigurosos especialistas. Debería ser un hecho incontrovertible que hace falta enmarcar esta subespecie teatral en el contexto histórico-cultural que la produjo, conforme a los planteamientos teóricos de la semiótica. No obstante, la gran difusión de la hermenéutica postmoderna, sobre todo en el área norteamericana, ha producido una abundante literatura crítica que prescinde, al menos en parte, de la contextualización histórico-cultural de los textos teatrales. Con razón Lía Schwartz 
ha hablado de "algunas tendencias narcisistas de la crítica postmoderna», debidas al "olvido de la historia» ${ }^{1}$.

Hace falta, pues, volver a remachar que la fiesta teatral del siglo XVII, sin llegar a ser una "anticomedia», constituye un subgénero específico del teatro coetáneo con sus propias normas y rasgos definitorios $^{2}$. De hecho, es una síntesis lograda de la fórmula de la comedia nueva y de los modelos cortesanos autóctonos (fastos, églogas de Juan del Encina, comedias por encargo de Torres Naharro, etc.) e italianos (desde la Favola d'Orfeo de Poliziano hasta Il pastor fido de Guarini), estos últimos relacionados con el estilo operístico ${ }^{3}$.

Esta clase de textos supone un circuito de comunicación dramática sui generis, ya que, con palabras de Díez Borque: «La fiesta cortesana emana del poder y se organiza con una intencionalidad y unas funciones bien definidas» ${ }^{4}$. El espacio para el cual se concibe, ya que se trate de un simple salón o del aparatoso Coliseo, implica una representación exclusiva para un público selecto, el «Senado» que se nombra tan a menudo en el remate de los versos de muchas piezas 5 , y que a veces incluye al propio monarca. En dichas circunstancias lo verdaderamente importante no es la obra en sí, sino que el rey sea admi-

${ }^{1}$ Schwartz, 2002; sobre esta candente cuestión por razones de espacio remito a Trambaioli, 1994 y 1997, así como a Fernández Mosquera, 2008a.

${ }^{2}$ Ver Oleza, 1986, p. 323, Neumeister, 1991 y Profeti, 2010, p. 304.

3 Ver Simson, 2000, p. 219: «Las fiestas mitológicas de Calderón [...] lograron crear una síntesis de la comedia, de la fiesta de corte previa, y de la ópera italiana. De la comedia vendrían la preferencia por el texto, y varios episodios y figuras; del espectáculo de corte, la ocasión, el encargo y la glorificación del rey; y la ópera italiana influiría en la fiesta mitológica con nuevos estilos musicales y un incremento de sus partes musicales»; Neumeister, 2000, p. 9: «La mitología clásica permite a Calderón y a sus contemporáneos encontrar la forma de integrarse en aquella moda de las fiestas cortesanas que, desde los trionfi de las ciudades-estado italianas, había contagiado a toda Europa».

${ }^{4}$ Díez Borque, 1994, p. 15.

5 Trambaioli, 2011, p. 193: «el Senado que Cascardi menciona como sinónimo del público del corral es, ante todo, el círculo reducido de nobles que asisten a los espectáculos particulares. No deja lugar a dudas la definición que del término nos ofrece Autoridades: "se toma por cualquier junta, o concurrencia de personas graves, respetables y circunspectas". No es por nada que la gran mayoría de las comedias reseñadas se cierra con una explícita referencia al "Senado", cuyos epítetos refuerzan la condición estamental: ilustre, gran, discreto, escogido, noble, famoso, doctísimo, generoso, devoto, cristiano". 
rado en la misma, ocupando el sitio de honor 6 . El escenario a la italiana, según cuyos principios se construye el Coliseo, contribuye plenamente a la exaltación monárquica. Sabemos de sobra que en este espacio dramático el punto de vista del rey va a coincidir con el punto della distanza que es el lugar privilegiado desde el cual se puede apreciar la perspectiva abarcando los puntos laterales del escenario ${ }^{7}$. Así, pues, el aparato escenográfico del Coliseo y de otros espacios análogos es un factor que moldea el texto teatral más allá de la voluntad del autor ${ }^{8}$.

El público de la comedia palaciega determina todo el circuito comunicativo teatral, y pese a que, posteriormente al estreno, la obra pueda pasar a la cartelera de los teatros públicos, donde necesita ser adaptada al nuevo espacio representacional ${ }^{9}$, de buenas a primeras se escribe para un conjunto de espectadores culturalmente homogéneo, que determina su factura poética y conformación dramática. La siguiente observación de Profeti acerca de la escritura de Juan del Encina para el entorno aristocrático de los duques de Alba mantiene toda su vigencia para los autores posteriores que regocijan a los Austrias menores:

le cose di cui si ragiona sono quelle che interessano ai destinatari, e nei modi che siano loro graditi: perció ogni operazione che tenti di effettuare uno spaccato sociologico in senso riduttivo di questo teatro è de-stinata allo scacco $[\ldots]$ mai come ora la ideologia della comunicazione sarà quella della classe dominante $[. .$.$] a fonti vulgate, conosciute alla piazza (sto-$ ria edificante-biblica) si sostituiscono fonti elitarie, conosciute solo alla sala (classicità greco-latina) ${ }^{10}$.

Los argumentos de las fiestas comisionadas suelen proceder, en efecto, de ámbitos literarios cultos contaminados entre sí: el bucólico-pas-

${ }^{6}$ Orgel, 1975, p. 16, afirma rotundamente que «the king must not merely see the play, he must be seen to see it».

${ }^{7}$ Sabbatini en su tratado no hace sino sistematizar una práctica ya corriente en las cortes italianas que, gracias a él y a todos los técnicos que irán a trabajar en el extranjero, se difundirá en el resto de Europa; ver Amadei-Pulice, 1990, p. 153.

${ }^{8}$ Ver Lobato, 2003, p. 257.

${ }^{9}$ Ver Shergold, 1967, p. 360. Para algunos aspectos de estos espectáculos de corte, ver Arellano, 1988.

10 Profeti, 1992, p. 9. 
toril, el mitológico y el caballeresco; en términos de análisis semiológico, los de las comedias cortesanas son mensajes estándares, con un nivel mínimo de información frente a los elementos redundantes, donde la originalidad deja lugar al gusto por descifrar material de sobra conocido $^{11}$. Por lo mismo, la dimensión metateatral es una de las peculiaridades textuales más relevantes de las piezas cortesanas. De hecho, los autores no solo juegan con el repertorio literario aludido, sino también con comedias propias o de otros poetas que el culto auditorio conoce al dedillo, de acuerdo con la práctica de la reescritura barroca. Entre muchos ejemplos que se podrían brindar, remito a la cadena dramática que juega en el nivel intertextual con Il pastor fido de Guarini, paradigma del melodrama europeo ${ }^{12}$ : El verdadero amante y $\mathrm{La}$ Arcadia de Lope, El pastor fido de Solís, Coello y Calderón ${ }^{13}$, y Fineza contra fineza del propio don Pedro son todos eslabones de la serie recortada $^{14}$. La conformación de semejantes cadenas textuales me viene como anillo al dedo para apuntar otro rasgo fundamental de la comedia palaciega: el de la ocasionalidad de las obras. Nacimientos, bautismos, cumpleaños, compromisos matrimoniales y bodas ${ }^{15}$, junto con el Carnaval, la noche de San Juan, acuerdos de paz y victorias, son las efemérides que se suelen celebrar con las fiestas teatrales, y los mitos e historias elaborados dramáticamente permiten crear un juego de espejos típicamente cortesano entre los hechos representados y la realidad coyuntural del público presente ${ }^{16}$. En el caso específico, la cadena textual mencionada se enmarca en una serie de celebraciones nupciales:

11 Ver Eco, 1980, p. 326: "probabilmente il territorio ideale della semiologia è quello dei messaggi a bassa quota di originalità (miti, fiabe, prodotti di massa)».

12 Ver Cecchi y Sapegno, 1976, p. 534: «l'idealizzazione della società cortigiana che egli dava per mezzo della finzione pastorale lo portava per una via tutta sua al di là delle eleganze madrigalesche verso quelle intonazioni melodrammatiche per le quali fino al Metastasio egli sarebbe rimasto un maestro ammiratissimo ed imitato".

13 Las piezas de consuno, subgénero de la fiesta teatral palaciega, destacan especialmente por el diálogo paródico con comedias anteriores; ver Calle González, 2002, p. 266, nota 16.

${ }^{14}$ Ver Trambaioli, 2010a.

15 Sobre esta específica ocasionalidad, ver Borrego Gutiérrez, 2003.

${ }^{16}$ Ver Trambaioli, 1995, pp. 217-240. 
si en 1598 Il pastor fido en Mantua sirve para celebrar el doble matrimonio de Alberto y Margarita de Austria, inaugurando una línea encomiástica dedicada a los matrimonios de los monarcas españoles, Lope, en sus huellas, compone una versión jocosa en ocasión de las dobles bodas regias de 1615 [La Arcadia], y, finalmente, los tres ingenios de la pieza homónima (Calderón, Solís y Coello) cierran el círculo paradigmático, festejando con mucha probabilidad las segundas nupcias del rey Felipe IV ${ }^{17}$.

Según vamos subrayando, las condiciones de producción y recepción del texto teatral cortesano reducen radicalmente la libertad poética del dramaturgo, y no solo el repertorio temático del cual él puede echar mano es restringido, sino que el encargo suele suponer la imposición del argumento para elaborar. Lo mismo vale con respecto a la adaptación del estilo operístico italiano al teatro español: apunta Simson que en las únicas tres óperas del siglo XVII, es decir La selva sin amor de Lope, La púrpura de la rosa y Celos, aun del aire, matan de Calderón, «la idea de crear obras totalmente cantadas no vino de los dramaturgos mismos, sino de iniciativas y círculos extraliterarios» ${ }^{18}$.

Así y todo, cada autor reelabora el repertorio literario según sus propias líneas de escritura, y si por un lado hay magnos poetas dramáticos, como Lope o Calderón, por otro hay segundones que trabajan para la corte ${ }^{19}$. Es decir, la fiesta cortesana es ante todo un espectáculo de recreo, además de ser un acto de auto-encantamiento de la sociedad cortesana ${ }^{20}$, pero todo esto no impide que el texto poético correspondiente pueda poseer su valor estético y literario. No es lo mismo hablar de algunas piezas de Lope o de muchas fiestas teatrales calderonianas y de ciertos libretti coetáneos que resultan ser el mero

17 Trambaioli, 2010a, p. 1373.

18 Simson, 2000, p. 219; Baczynska, 2011, p. 35, por su parte, insinúa la posibilidad de que hasta en el caso de las piezas sacramentales, que al fin y al cabo son obras de encargo, la elección del argumento no fuera del dramaturgo: «en general desconocemos el grado de autonomía de Calderón a la hora de decidir los temas de los autos».

${ }^{19}$ A propósito de Los tres mayores prodigios, escribe Fernández Mosquera, 2008b, p. 176: «Sí, Calderón escribió muy seriamente una obra que quería provocase diversión, a diferencia de aquellos malos poetas cortesanos que componían frívolamente comedias de severo trasfondo trágico».

${ }^{20}$ Ver Amadei-Pulice, 1990, p. 152, y Tintelnot, 1955, p. 240; este último subraya además que "perfino la sacra imperiale maestà rappresenta se stessa» (p. 241). 
pretexto para montar espectáculos de tramoya y música. A continuación, para seguir perfilando el código dramático de las fiestas cortesanas, creo oportuno ahondar en las personales prácticas teatrales de Lope y Calderón, porque, de hecho, representan y ejemplifican respectivamente los modelos heterodoxo y ortodoxo del poeta que trabaja para la nobleza y la corte españolas.

El caso del Fénix es más complejo, porque, aun no siendo el dramaturgo oficial de palacio, de su pluma se aprovechan tanto los círculos nobiliarios en cuyo entorno se mueve en las distintas fases de su larga carrera artística, como la propia familia real. Las obras que compone para estos dos distintos contextos palaciegos obedecen a criterios temáticos y representacionales diferentes, conformando dos subtipos de la fiesta teatral.

En primer lugar cabe recordar un teatro de cámara ${ }^{21}$ muy distinto al drama de gran aparato y de tramoya realizable solo en el espacio teatral a la italiana, cuyos argumentos abarcan un abanico muy parecido al de la comedia nueva. No obstante, en este repertorio destacan dos tipologías temáticas bien específicas, dirigidas respectivamente a los nobles y a las damas del distinguido Senado que asiste a las representaciones: por un lado, las piezas de hechos famosos que, por lo general, llegan a coincidir con la comedia genealógica, cuyo propósito es claramente panegírico 22 ; por otro, las comedias de ambientación urbana, las cuales, pese a brindar al espectador un trasfondo coetáneo y doméstico, presentan un entramado de épica amorosa que desrealiza el enredo conforme a los gustos literarios específicos del público aristocrático femenino ${ }^{23}$. Arata llama la atención sobre la "“cortesanización" de algunos géneros teatrales como la comedia urbana de ambiente madrileño» ${ }^{24}$, tendencia que se empieza a producir a lo largo del Quinientos, y que Lope sabe perfeccionar con maestría.

${ }^{21}$ Ver Trambaioli, 2011.

22 Ver Ferrer Valls, 1991b y 1993, y Zugasti, 1998.

23 Sobre este argumento llevo años recogiendo material en un corpus relevante de comedias de ambientación urbana de Lope que pronto verá la luz bajo la forma de una monografia: La épica de amor en las comedias de ambientación urbana de Lope de Vega (¿subgénero del teatro cortesano?).

${ }^{24}$ Arata, 2002, pp. 226-227. 
Aunque la composición o estreno de las obras que forman parte de este teatro de cámara no se recoge en relaciones y documentos, el destino cortesano de las mismas se puede inferir de la factura poética, sobre todo de las referencias panegíricas, y de algunas características compositivas. Brindemos el caso ya mencionado de La Arcadia, pieza supuestamente de $1615^{25}$. Solo podemos considerar la hipótesis de que sea fruto de un encargo recibido para algún festejo organizado por el duque de Lerma con motivo de las dobles bodas dinásticas de ese mismo año en que el Fénix es muy activo como dramaturgo cortesano $^{26}$. De ser así, tal vez se pudo representar en la huerta madrileña que el valido de Felipe III había hecho aderezar para la diversión de la corte, sobre la cual ha reflexionado Arata ${ }^{27}$.

En segundo lugar, tenemos algunas noticias de encargos oficiales que se hicieron a Lope desde palacio: El premio de la hermosura, El vellocino de oro, La selva sin amor y El amor enamorado. Algunas de estas comedias fueron ejecutadas por miembros de la familia real y de la nobleza; el Vellocino, por ejemplo, fue representado el 16 de mayo de 1622 por una cuadrilla de damas, encabezadas por doña Leonor Pimentel ${ }^{28}$. Profeti utiliza el rótulo atinado de «fiesta de damas» para referirse a esta específica práctica representacional ${ }^{29}$; Lobato recoge datos que documentan más en general la afición de la aristocracia coetánea por el arte histriónico ${ }^{30}$.

Se suele creer que el Fénix, viviendo con desasosiego el paso del teatro de palabra al espectáculo visual, menosprecia el fasto escénico cortesano, sacando a colación comentarios esparcidos en su escritura. En realidad, lo que dice precisamente en la dedicatoria de La selva sin amor al Almirante de Castilla — «lo menos que en ella hubo fueron mis versos $»^{31}$ — no es más que el manido recurso retórico a la excu-

25 Con respecto a la factura cortesana de La Arcadia, ver Ferrer Valls, 1995, pp. 222 y 228.

${ }^{26}$ Acerca de la producción teatral vinculada con este acontecimiento, ver Ferrer Valls, 1991a, p. 125 y Trambaioli, 2010b.

27 Arata, 2002.

28 Ver Ferrer Valls, 1996, p. 51.

${ }^{29}$ Profeti, 2000.

${ }^{30}$ Lobato, 2007.

${ }^{31}$ Lope de Vega, La selva sin amor, p. 65; ver Profeti, en «Introduzione», p. 20: «va riconsiderato l'atteggiamento di sufficienza se non di dispregio che Lope talora ma- 
satio propter infirmitatem funcional al contexto panegírico en que se inserta. El viejo Lope entiende que la maquinaria escénica puede hacer resaltar sus versos, y tiene toda la conciencia y sabiduría estéticas para saber adaptar su pluma poética al estilo representativo a la italiana, construyendo el tejido poético en función de las potencialidades de la partitura musical. Explica Profeti al respecto: «Nel testo letterario di Lope si sarà già notata l'abilità di costruzione in funzione delle potenzialità della musica» ${ }^{32}$. Recordemos que aquí el Fénix deja de lado la gran innovación de su fórmula teatral, que representa el desarrollo de la tragicomedia al estilo de La Celestina ${ }^{33}$, para acercarse al patrón de la tragicommedia italiana que realiza una mezcla de géneros menos radical que la de la comedia española, la del estilo "polito" con el "grave» para decirlo con Guarini ${ }^{34}$. A fin de cuentas, lo que Lope comparte especialmente con el autor de Il pastor fido es la concepción musical de los versos, junto con una visión hedonista del texto dramático ${ }^{35}$.

En cuanto a la ocasionalidad de sus comedias de cámara y fiestas cortesanas, el poeta, por sus ambiciones palaciegas, inserta verdaderas relaciones de los acontecimientos que interrumpen el desarrollo de la acción. Por ejemplo, en Los ramilletes de Madrid el protagonista (Marcelo) y Lucindo, ambos máscaras teatrales del poeta, actúan como cronistas del ostentoso acompañamiento de las dos princesas hasta la frontera con Francia para la doble celebración matrimonial de $1615^{36}$.

nifesta nei riguardi della scenografia, come nella tanto ripetuta dichiarazione del prologo della Decimasexta parte: la consapevolezza di diversi destinatari e di diverse possibilità di allestimento è sempre presente agli occhi del creatore, che non mancherà di inorgoglirsi per l'eleganza ed il fasto che "premiano" i suoi testi»; a propósito del Prólogo dialogístico mencionado, ver Ferrer Valls, 1991a, p. 97.

${ }^{32}$ Ver La selva sin amor, ed. Profeti, pp. 29 y 36.

33 Pérez y Sánchez Escribano, 1961, p. 209, nota 473.

${ }^{34}$ Ver Trambaioli, 2010d, p. 1017.

${ }^{35}$ Ver Trambaioli, 2010d, pp. 1018 y 1019: «Dos aspectos teóricos fundamentales que los dos poetas comparten plenamente son la concepción hedonista del arte y la extremada atención a los gustos del público. Tanto para Guarini como para Lope el fin principal de la poesía dramática es el deleite estético, que ambos vinculan al relativismo del gusto que va cambiando con el paso del tiempo [...] Otro elemento sobresaliente que Guarini y Lope tienen en común es la estilización en clave musical del lenguaje lírico tradicional».

${ }^{36}$ Ver Trambaioli, 2006, p. 147. 
Con todo, el teatro cortesano de Lope a veces se sale de las normas del género, porque el madrileño, por sus ansias frenéticas de autopromoción, en lugar de esperar a que le encarguen la composición de una pieza con finalidades encomiásticas, toma él mismo la iniciativa, metiendo la pata. Es lo que ocurre con algunas comedias genealógicas, tales como Los Porceles de Murcia y El valiente Céspedes ${ }^{37}$. Otras veces habla demasiado de sus propias instancias mediante la presencia, en ocasiones obsesiva, de proyecciones dramáticas de su persona hasta en fiestas cortesanas oficiales - pensemos tan solo en El premio de la hermosura, donde el jardinero Fabio, con tono quejumbroso, de forma oblicua pide la plaza de cronista a los reyes presentes en el estreno-, con el resultado de quedar excluido del circuito oficial de la comunicación teatral palaciega ${ }^{38}$. Prueba de ello es el fracaso de su ambición de conseguir el cargo de cronista regio. Apunto de nuevo con Profeti que «l'emittente rischia l'estromissione dalla sala qualora non effettui una oculata scelta dei temi e non li svolga in maniera "gradita" ${ }^{39}$.

Calderón de la Barca, a diferencia del Fénix, no escribe para un indistinto Senado, sino directamente para la corte del rey Planeta, empezando bajo la égida de Olivares, quien hace construir el Coliseo y organiza los festejos monárquicos con vistas a promover a Felipe IV como el núcleo central de la cultura y de la política coetáneas ${ }^{40}$. El mayor encanto, amor y Los tres mayores prodigios, ambas representadas en los jardines y estanques del Retiro cuando todavía el Coliseo existía solo en los proyectos del valido, son frutos tempranos de su oficio cortesano $^{41}$.

Posteriormente, cuando es ya dramaturgo de cámara del rey, don Pedro recibe los encargos de Gaspar de Haro, ministro y gobernador del Palacio del Buen Retiro. Stein destaca que este noble es un «afi-

37 A propósito de la segunda comedia mencionada, ver Ferrer Valls, 1998, p. 224.

${ }^{38}$ Ver Trambaioli, 2010c, pp. 557-558: «cabe reconocer que, por lo menos en algunos casos, la aproximación exagerada de sus autorretratos dramáticos al público hace que sus cuadros teatrales resulten verdaderamente desaforados e inaceptables para el ojo del espectador cortesano".

39 Profeti, 1992, p. 10.

${ }^{40}$ Ver Brown y Elliott, 1981, p. 30.

${ }^{41}$ Las dos piezas fueron estrenadas respectivamente el 29 de julio de 1635 y la noche de San Juan de 1636. 
cionado de las actividades culturales y promotor de fiestas mitológicas y zarzuelas con música", y sospecha que es él quien escoge los argumentos de las óperas calderonianas La púrpura y Celos, considerando que en las habitaciones particulares de Felipe IV se hallaban dos cuadros del pintor veneciano Veronese que ilustraban las mismas fábulas mitológicas ${ }^{42}$. No tenemos por qué pensar que con las demás piezas de tema grecorromano ocurriera algo distinto.

Por lo general, la actitud del Calderón cortesano es muy diferente de la de Lope. Ante todo, en lugar de insertar largas relaciones de los regios acontecimientos, es un maestro en diseminar referencias capaces de aludir a la coyuntura celebrativa en el texto de sus comedias. Por ejemplo, en Eco y Narciso, cuyas primeras escenas están dedicadas al cumpleaños de la ninfa y, por extensión, de Margarita, los actores que encarnan a Silvio, Febo y Bato rinden homenaje a la hermosa protagonista en términos panegíricos, mirando desde el escenario a la infanta festejada.

Acerca de la estructura de sus piezas cortesanas, cabe destacar de paso una tendencia a recuperar la presencia de cuadros de espectacularidad autónoma típicos de la práctica escénica quinientista, aspecto que todavía no ha sido puesto de relieve de forma adecuada ${ }^{43}$.

En tercer lugar, se ha hecho hincapié en la carta que el dramaturgo envió a Cosimo Lotti para explicarle que no podía aceptar su plano escenográfico por no respetar su concepción dramática ${ }^{44}$. A diferencia de Lope, pues, Calderón no concibe su teatro palaciego desde un punto de vista esencialmente estético. Por lo mismo, se niega a adaptar realmente su estilo poético, tan embebido de retórica y símbolos, al teatro operístico "tutto in musica», razón por la cual en el siglo XVII después de Púrpura y Celos en España no se vuelve a experi-

42 Stein, 1993, pp. 208 y 213.

43 En Trambaioli, 1998, p. 291, aislaba «los largos paréntesis cómicos de tono entremesil, presentes en los textos teatrales de El mayor encanto, amor (1635), Fortunas de Andrómeda y Perseo (1653), El laurel de Apolo (1658), Celos, aun del aire, matan (1660)»; y concluía observando que Calderón, de esta manera: «se acerca, en alguna medida, al espíritu de la comedia prelopista incorporando en el tejido dramático largos episodios de pura tonalidad entremesil» (p. 303); a este propósito, ver también la contribución de Escudero, en prensa.

44 Rouanet, 1899; Varey, 1967; Egido, 1995, pp. 106-118. 
mentar en esa dirección. De nuevo lo explica con claridad Profeti, hablando del lenguaje poético de estas óperas calderonianas: «la sua fruizione piena si dà solo attraverso lo spazio della dizione, che permette allo spettatore di decifrare i rimandi al patrimonio retorico e simbolico tanto ampiamente esibito" ${ }^{45}$.

Según advierte Neumeister, Calderón intenta «conciliar la teoría musical cristiana con las formas del nuevo teatro de ostentación", creando «un género dramático-musical único: eclipsa no solo las representaciones festivas cortesanas sino también la ópera de la época, mediante una concepción que sabe enlazar el efecto estético con la significación filosófica» ${ }^{46}$.

Desde un punto de vista estrictamente musical, más que alternar arias y recitativo, Calderón prefiere recurrir al coro, al igual que hace en los autos sacramentales; conforme a su intencionalidad pedagógica, según hace notar Miquel Querol, «Calderón confía al coro la misión de grabar, en el ánimo de los actores que representan y en el público que escucha, la sentencia o moraleja que deberá recordar y tener presente» ${ }^{47}$. Ya con anterioridad Peter Daly había apuntado lo mismo, destacando que "the chorus corresponds to the subscriptio of an emblem $»^{48}$. Cierto es que varios fragmentos de las comedias mitológicas de don Pedro son verdaderos emblemas dramáticos ${ }^{49}$.

No olvidemos que el Calderón dramaturgo de cámara de Felipe IV es un sacerdote, muy consciente de su rol, y que en la España del siglo XVII, caracterizada por la visión confesional del mundo, el sacerdote, en cuanto «hombre diferenciado y diferente», «estaba llamado a encarnar el tipo ideal, suerte de imán capaz de conducir a los hombres desde lo más bajo a lo más sublime», tal como destaca Luciana Gentilli50.Y con George Güntert quisiera llamar la atención sobre el hecho de que «La religiosidad de Calderón [...] se inscribe en el tex-

45 Profeti, 1998, p. 119; ver también Cancelliere, 2010, y Güntert, 2011, p. 25: «Lo "barroco" del estilo de Calderón deriva, en particular, del carácter menos mimético que metafórico y metonímico de su idiolecto».

46 Neumeister, 2000, p. 66.

47 Querol, 1981, p. 13.

48 Daly, 1979, p. 162.

${ }^{49}$ Ver Trambaioli, 1997.

${ }^{50}$ Gentilli, 2011, p. 124. 
to como un saber secreto, cifrado, sí, pero accesible: como una sabiduría irónica que trasciende el mundo terreno» ${ }^{51}$.

Sin embargo, adviértase que la seriedad y la coherencia autorial con que Calderón lleva a cabo los encargos, como ya queda dicho, no corresponde necesariamente a la voluntad de producir un teatro trágico, género que por muchos aspectos termina resultando incompatible con la ocasionalidad festiva ${ }^{52}$. Aun rechazando el hedonismo italianizante que tanto armoniza con el estilo lopesco, el dramaturgo de la segunda promoción sabe perfectamente que la fiesta teatral es una ocasión de entretenimiento y de diversión. Prueba de ello es el gran derroche de comicidad chocarrera — se trata de verdaderos entremeses- que se puede aislar en sus comedias cortesanas ${ }^{53}$.

Beata Baczynska subraya que cuando el poeta dejó de colaborar con el teatro público a partir de 1650 «escribía autos por encargo del Ayuntamiento y empleaba su "habilidad e ingenio" para el alivio de los cuidados del rey o, más bien, la diversión de la joven reina». Y a propósito de Afectos de odio y amor, comedia compuesta para las Carnestolendas de 1658, asienta que la finalidad de esta suerte de «political fiction al uso de la época» - recordemos que la trama versa sobre la figura histórica de la reina Cristina de Suecia- «era hacerle gracia al rey, aquejado de los males de la monarquía, y — ¿por qué no?- hacer sonreír a la joven reina Mariana, la infanta María Teresa y las damas de honor de la corte» ${ }^{54}$. El riguroso planteamiento de Baczynska, que nunca pierde de vista el contexto en el cual y para el cual escribe el autor, apunta a que Calderón, en cuanto asalariado del rey, puede reivindicar su autonomía para servir con su arte, pero no puede (ni desea) criticar nada del poder establecido.

En conclusión, diríase que Lope y Calderón frente a frente nos deparan dos tipologías bien distintas de autores cortesanos, pero, pese a las diferentes concepciones teatrales, sus piezas palaciegas responden a

51 Güntert, 2011, p. 23; ver Neumeister, 2000, p. 39: «El gran racionalista entre los dramaturgos del Siglo de Oro utiliza el mito y la alegoría antes bien para expresar lo inefable, los misterios de nuestra existencia y de la creación en general. Lo hace, para citar [...] a Boccaccio, "sub cortice fabularum", en la fiesta de corte, o "more allegorico", en el auto sacramental».

52 Ver a dicho propósito Trambaioli, en prensa.

${ }^{53}$ Ver Trambaioli, 1998.

54 Baczynska, 2012, respectivamente pp. 25 y 43. 
los rasgos y normas que hemos venido resumiendo en las páginas anteriores, con algún que otro desliz por parte del Fénix. No hay vuelta de hoja: el teatro cortesano remite a un patrón bien distinto del de la comedia nueva, pero para tener en cuenta sus leyes propias no podemos pasar por alto las coordenadas histórico-culturales en que a sus autores les tocó vivir así como los mecanismos universales de la máquina del poder. Y voy a rematar estas páginas con una reflexión que Güntert dedica a La vida es sueño, pero que se puede aplicar sin más a las comedias cortesanas del Barroco español: «Es muy posible que las soluciones políticas no satisfagan a los espectadores modernos: resultan no obstante perfectamente adecuadas en el contexto sociológico que describe Calderón» ${ }^{55}$.

55 Güntert, 2011, p. 30. 


\section{BiBLIOGRAFÍA}

Amadei-Pulice, M. A., Calderón y el Barroco. Exaltación y engaño de los sentidos, Amsterdam / Philadelphia, John Benjamins Publishing Company, 1990.

Arata, S., «Proyección escenográfica de la huerta del duque de Lerma en Madrid», en Textos, géneros, temas. Investigaciones sobre el teatro del Siglo de Oro y su pervivencia, ed. F. Antonucci, L. Arata y M. ${ }^{a}$ del V. Ojeda, Pisa, Edizioni ETS, 2002, pp. 211-229.

Arellano, I., "Bances Candamo, poeta áulico. Teoría y práctica en el teatro cortesano del postrer Siglo de Oro», Iberoromania, 27-28, 1988, pp. 42-60.

BACzynska, B., «Calderón de la Barca o la renuncia a la autonomía: de la comedia al auto sacramental, del auto sacramental a la comedia», en El autor en el Siglo de Oro. Su estatus intelectual y social, ed. M. Tietz y M. Trambaioli, Vigo, Editorial Academia del Hispanismo, 2011, pp. 23-49.

Borrego Gutiérrez, E., «Matrimonios de la casa de Austria y fiesta cortesana», en La fiesta cortesana en la época de los Austrias, ed. M. ${ }^{a}$ L. Lobato y B. J. García García, Valladolid, Junta de Castilla y León, Consejería de Cultura y Turismo, 2003, pp. 79-115.

Brown, J., y J. H. Elliott, Un palacio para el rey. El Buen Retiro y la corte de Felipe IV, Madrid, Revista de Occidente / Alianza Editorial, 1981.

Calle González, S., "Calderón y las comedias de varios ingenios: los enredos de una fábula», en Calderón 2000. Homenaje a Kurt Reichenberger en su 80 cumpleaños, ed. I. Arellano, Kassel, Reichenberger, 2002, vol. I, pp. 263276.

Cancelliere, E., "Pandora: mito e icono para una fiesta real», Anuario calderoniano, 3, 2010, pp. 67-85.

Cecchi, E., y N. Sapegno, Storia della Letteratura Italiana. IV. Il Cinquecento, Milano, Garzanti, 1976.

Díez-Borque, J. M. ${ }^{\text {a }}$, «Fiesta y teatro en la Corte de los Austrias», en Barroco español y austríaco: Fiesta y Teatro en la Corte. Catálogo de la Exposición del mismo título celebrada en el Museo Municipal de Madrid en abril-junio 1994, ed. J. M. ${ }^{a}$ Díez Borque y K. F. Rudolf, Madrid, Museo Municipal, 1994, pp. 15-31.

Egido, A., El gran teatro de Calderón. Personajes, temas, escenografía, Kassel, Reichenberger, 1995.

Fernández Mosquera, S., «El significado de las primeras fiestas cortesanas de Calderón de la Barca», en Calderón y el pensamiento ideológico y cultural de su época. XIV Coloquio Anglogermano sobre Calderón (Heidelberg, 24-28 de 
julio de 2005), ed. M. Tietz y G. Arnscheidt, Stuttgart, Franz SteinerVerlag, 2008a, pp. 209-232.

— «Las comedias mitológicas de Calderón: entre la fiesta y la tragedia. El caso de Los tres mayores prodigios», en Hacia la tragedia áurea. Lecturas para un nuevo milenio, ed. F. A. De Armas, L. García Lorenzo y E. García SantoTomás, Madrid / Frankfurt, Iberoamericana / Vervuert, 2008b, pp. 153179.

Ferrer Valls, T., La práctica escénica cortesana: de la época del emperador a la de Felipe III, London, Tamesis Books, 1991a.

— «Lope de Vega y el teatro por encargo: plan de dos comedias», en Comedias y comediantes. Estudios sobre el teatro clásico español, ed. M. V. Diago y T. Ferrer Valls, València, Universitat de València, Departament de Filologia Espanyola, 1991b, pp. 189-199.

- Nobleza y espectáculo teatral (1535-1622). Estudios y documentos, València, UNED / Universidad de Sevilla / Universitat de València, 1993.

— «Teatro y representación cortesana. La Arcadia de Lope de Vega: una hipótesis de puesta en escena», en La puesta en escena del teatro clásico, Cuadernos de Teatro Clásico, 8, 1995, pp. 213-232.

- "El vellocino de oro y El amor enamorado», en En Torno al teatro del Siglo de Oro. Actas de las XII-XIII Jornadas de Almería, ed. J. Berbel, H. Castellón, A. Orejudo y A. Serrano, Almería, Instituto de Estudios Almerienses / Diputación de Almería, 1996, pp. 49-63.

— «Lope de Vega y la dramatización de la materia genealógica (I)», en Teatro cortesano en la España de los Austrias, ed. J. M. ${ }^{a}$ Díez Borque, Cuadernos de Teatro Clásico, 10, 1998, pp. 215-231.

Gentilli, L., «Entre el ser y el deber ser: el debate sobre la (re)-formación y la identidad modélica en los diferentes estados en la España del siglo XVII", en El autor en el Siglo de Oro. Su estatus intelectual $y$ social, ed. M. Tietz y M. Trambaioli, Vigo, Editorial Academia del Hispanismo, 2011, pp. 117127.

Güntert, G., La comedia de Calderón: discurso social y sabiduría poética, Vigo, Editorial Academia del Hispanismo, 2011.

LobAto, M. ${ }^{a}$ L., "Literatura dramática y fiestas reales en la España de los últimos Austrias", en La fiesta cortesana en la época de los Austrias, ed. M. ${ }^{a}$ L. Lobato y B. J. García García,Valladolid, Junta de Castilla y León, Consejería de Cultura y Turismo, 2003, pp. 251-271.

- «Nobles como actores. El papel activo de las gentes de palacio en las representaciones cortesanas de la época de los Austrias», en Dramaturgia festiva y cultura nobiliaria en el Siglo de Oro, ed. B. J. García García y M. ${ }^{a}$ L. Lobato, Madrid / Frankfurt, Iberoamericana / Vervuert, 2007, pp. 89-114. 
Neumeister, S., "La fiesta de corte como anticomedia», en Espacios teatrales del Barroco español: calle-iglesia-palacio-universidad, ed. J. M. ${ }^{a}$ Díez Borque, Kassel, Reichenberger, 1991, pp. 167-181.

- Mito clásico y ostentación. Los dramas mitológicos de Calderón, Kassel, Edition Reichenberger, 2000.

OlezA, J., "Adonis y Venus. Una comedia cortesana del primer Lope de Vega», en Teatro y prácticas escénicas. II: La comedia, ed. J. L. Canet Vallés, London, Tamesis, 1986, pp. 309-324.

Orgel, S., The Illusion of Power. Political Theater in the English Renaissance, London / Berkeley / Los Angeles, University of California Press, 1975.

Pérez, L. C., y F. Sánchez Escribano, Afirmaciones de Lope de Vega sobre preceptiva dramática a base de cien comedias, Madrid, CSIC, 1961.

Profeti, M. G., «Luogo teatrale e scrittura: il teatro di Juan del Encina», en La vil quimera de este monstruo cómico,Verona / Kassel, Università degli Studi di Verona / Reichenberger, 1992, pp. 3-19.

— « Registri letterari e registri teatrali. Risemantizzazione di un mito: La púrpura de la rosa», en Calderón: testo letterario e testo spettacolo, Firenze, Alinea Editrice, 1998, pp. 102-119.

— «Fiestas de damas», Salina, 14, 2000, pp. 79-90.

— «Calderón y la ópera italiana», Anuario calderoniano, 3, 2010, pp. 295-306.

Querol, M., Teatro musical de Calderón. Estudio, transcripción y realización del acompañamiento, Barcelona, Dirección General de Música y Teatro del Ministerio de Cultura, 1981.

Rounnet, L., «Un autographe inédit de Calderón», Revue Hispanique, 6, 1899, pp. 197-200.

SCHWARTz, L., "De hispanismo, los siglos XVI y XVII y el olvido de la historia», Ciberletras. Revista de crítica literaria y de cultura, 6, 2002, en <www.lehman.cuny.edu/ciberletras/v06/liaschwartz.html>.

Shergold, N. D., A History of the Spanish Stage, Oxford, Clarendon Press, 1967.

Simson, I., "Calderón como libretista: representaciones musicales del Siglo de Oro», en Calderón protagonista eminente del Barroco europeo, ed. K. y T. Reichenberger, Kassel, Reichenberger, 2000, vol. I, pp. 217-243.

Stein, L. K., Songs of Mortals, Dialogues of the Gods. Music and Theatre in Seventheenth-Century Spain, Oxford, Clarendon Press, 1993.

Tintelnot, H., "Annotazioni su l'importanza della festa teatrale per la vita artistica e dinastica nel Barocco", en Retorica e Barocco. Atti del II Congresso Internazionale di Studi Umanistici, ed. E. Castelli, Roma, Fratelli Bocca Editori, 1955, pp. 233-241. 
Trambaiol, M., Funcionalidad del mito clásico en las fiestas cortesanas de Calderón, Tesis doctoral, University of Illinois, 1994.

- «La funcionalidad panegírica de la mitología en las fiestas palaciegas de Calderón», Annali dell'Istituto Universitario Orientale, Sezione Romanza, 37, núm. 1, 1995, pp. 217-240.

— «Las "empresas” dramáticas calderonianas de tema mitológico sobre la educación del perfecto príncipe cristiano", en Actes du Congrès International Théâtre, Music et Arts dans les Cours Européennes de la Renaissance et du Baroque (Varsovia, 23-28 de septiembre de 1996), ed. K. Sabik, Varsovie, Université de Varsovie, Faculté des Lettres Modernes, 1997, pp. 269-286.

— «Tonalidades entremesiles en el teatro palaciego de Calderón», en Calderón: Testo letterario e testo spettacolo, Firenze, Alinea Editrice, 1998, pp. 287-303.

- «Una pre-Dorotea circunstancial de Lope de Vega: Los ramilletes de Madrid. II. Las polémicas literarias y la dimensión política», Criticón, 96, 2006, pp. 139-152.

- «Il pastor fido de Battista Guarini: paradigma privilegiado de la comedia cortesana en la España de los Austrias», en Centros de poder italianos en la monarquía hispánica (siglos XV-XVIII). Congreso Internacional (Madrid, 10-12 de diciembre de 2008), ed. J. Martínez Millán y M. Rivero Rodríguez, vol. II, Madrid, Ediciones Polifemo, 2010a, pp. 1337-1373.

- «Las dobles bodas reales de 1615: el triunfo del Lope-personaje sobre el Lope cortesano», Bulletin of Hispanic Studies, 87, núm. 7, 2010b, pp. 755772 .

— «ope in fabula: el Fénix pintado por sí mismo en el marco dramático de su teatro cortesano», en Cultura oral, visual y escrita en la España de los Siglos de Oro, ed. I. Osuna y E. Llergo, Madrid, Visor Libros, 2010c, pp. 537563.

- «Lope de Vega ante la tragicommedia de Giovan Battista Guarini», en Cuatrocientos años del "Arte nuevo de hacer comedias" de Lope de Vega. Actas selectas del XIV Congreso de la Asociación Internacional de Teatro Español y Novohispano de los Siglos de Oro (20-23 de julio de 2009), ed. G. Vega García-Luengos y H. Urzáiz Tortajada, Valladolid / Olmedo, Universidad de Valladolid / Ayuntamiento de Olmedo, 2010d, pp. 1013-1023.

— "Aquí, Senado, se acaba...": normas implícitas y rasgos dramáticos del teatro de cámara de Lope de Vega", en Norme per lo spettacolo / Norme per lo spettatore. Teoria e prassi del teatro intorno all "Arte Nuevo», ed. G. Poggi y M. G. Profeti, Firenze, Alinea Editrice, 2011, pp. 185-198.

- «La fiesta teatral cortesana de la España barroca y el género trágico», en prensa. 
Varey, J. E., "Calderón, Cosme Lotti, Velázquez, and the Madrid Festivities of 1636-1637», Renaissance Drama, I, 1967, pp. 273-282.

VegA, Lope de, La selva sin amor, ed. M. G. Profeti, Firenze, Alinea Editrice, 1999.

Zugasti, M., "Órbitas del poder, encargo literario y drama genealógico en el Siglo de Oro: de Encina a Lope de Vega», en El drama histórico. Teoría y comentarios, ed. K. Spang, Pamplona, Eunsa, 1998, pp. 129-157. 